\title{
Single Lap Joints Numerical Modelling and Comparison with Experimental Testing
}

\author{
Daniel F. O. Braga ${ }^{1}$, Lucas F. M. da Silva², Pedro M. G. P. Moreira ${ }^{1}$ \\ 1 Institute of Science and Innovation in Mechanical and Industrial Engineering (INEGI), \\ University of Porto, Porto, Portugal (dbraga@inegi.up.pt); 2Department of Mechanical \\ Engineering, Faculty of Engineering University of Porto, Porto, Portugal (lucas@fe.up.pt)
}

\begin{abstract}
Adhesive bonding is a joining technique which has been extensively employed in structural design as its ability to join different types of materials allows higher freedom for designers when choosing materials. One of the most common joint configuration used is the single lap joint configuration. In this work a set of experimental procedures were undertaken to characterize a structural adhesive and model the behaviour of a single lap joint manufactured using this adhesive. Two types of surface preparations were used to study its effect in single lap joint strength.
\end{abstract}

Subject Headings. Technological Process, Resistance of Materials

Author Keywords. Numerical Modelling, Adhesive Bonding

\section{Introduction}

Application of adhesive bonded joints has developed over the last decades as adhesive bonded joints offer interesting characteristics. Along with increase industrial application potential, adhesives have been the focus of study of many researchers. Some examples of research topics in this field are; adhesive properties and applications at high and low temperatures (Marques et al. 2015, Xie et al. 2015, Xia et al. 2014), adhesive ageing (Pethrick 2014), adhesive joints fracture characterization (Chaves et al. 2014), development and validation of numeric simulation tools (Gonçalves et al. 2014, Campilho, Banea, and da Silva 2013, Sauer 2015), self-healing and thermally expandable particles in adhesive (Banea et al. 2014, Gu and Zacharia 2015), application cases (Kadioglu and Adams 2015, Schiel et al. 2015), along with other topics.

Compared with other joining techniques adhesive bonding results in less stress concentrations, higher vibration damping and fatigue strength. Therefore, accurately predicting joints' strength is essential. When stress singularities are present the stress based methods are not adequate to predict failure nor do they allow obtaining the failure paths. Overcoming these limitations, fracture mechanics approach is frequently applied by means of an energetic analysis. Determination of the critical fracture energies $\left(J_{i c}, i=I, I I\right)$ and the respective cohesive laws is essential in order to use fracture mechanics approach in predicting failure of adhesive joints.

Fracture behaviour of bonded joints in mode I (loading normal to the crack) has been studied by several authors. Andersson and Stigh in (Andersson and Stigh 2004) determined the cohesive parameters of a ductile adhesive with an inverse method in double cantilever beam specimens. For mode II (shear loading along the crack) fracture characterization end notched flexure test is widely used. When studying mode II fracture characterization of adhesive joints through 2-D numerical modelling de Moura in (De Moura 2006) concluded that the data reduction schemes based on beam theories produced some non-negligible errors. A new data 
reduction scheme including the fracture process zone effects and not depending on the crack length was then proposed. In (Campilho et al. 2008), a trapezoidal cohesive damage model appropriate for ductile adhesives in adhesively bonded joints was presented. Double Cantilever Beam (DCB) and End Notched Flexure (ENF) tests were used in order to obtain the cohesive laws of the Araldite ${ }^{\circledR} 2015$ adhesive in pure modes I and II, respectively. In order to obtain $J_{\text {ic }}(\mathrm{i}=\mathrm{I}, \mathrm{II})$ in mode I and II from DCB and ENF tests respectively and the remaining cohesive parameters through an inverse method compliance based beam method was used. This work aims to characterize a structural adhesive Araldite $\mathrm{T}^{\mathrm{TM}} 420$ and create a model capable of predicting failure of single lap joints using this epoxy adhesive. Two different surface treatments were tested (sand blasting and phosphoric acid anodization) for bond strength.

\section{Experimental Procedure}

\subsection{Adhesive characterization}

The structural adhesive used in this study is a two part epoxy adhesive, Araldite ${ }^{\mathrm{TM}} 420$ supplied by Hunstman ${ }^{\circledR}$ (Salt Lake City, UT, USA). To assess ultimate tensile strength (UTS) as well as estimate the stiffness of the adhesive material when cured, bulk tensile specimens were manufactured and tested according to standard ASTM D638. The specimens were manufactured in a metallic mould shown in Figure 1 and cure temperature was monitored through a k-type thermocouple embedded in adhesive. The specimens' thickness was controlled through a silicone rubber spacer with $2 \mathrm{~mm}$ thickness. Three cures were done, a room temperature cure for 2 weeks, a $165^{\circ} \mathrm{C}$ for 30 minutes and a $200^{\circ} \mathrm{C}$ for 30 minutes. After curing the specimens were milled to specification.

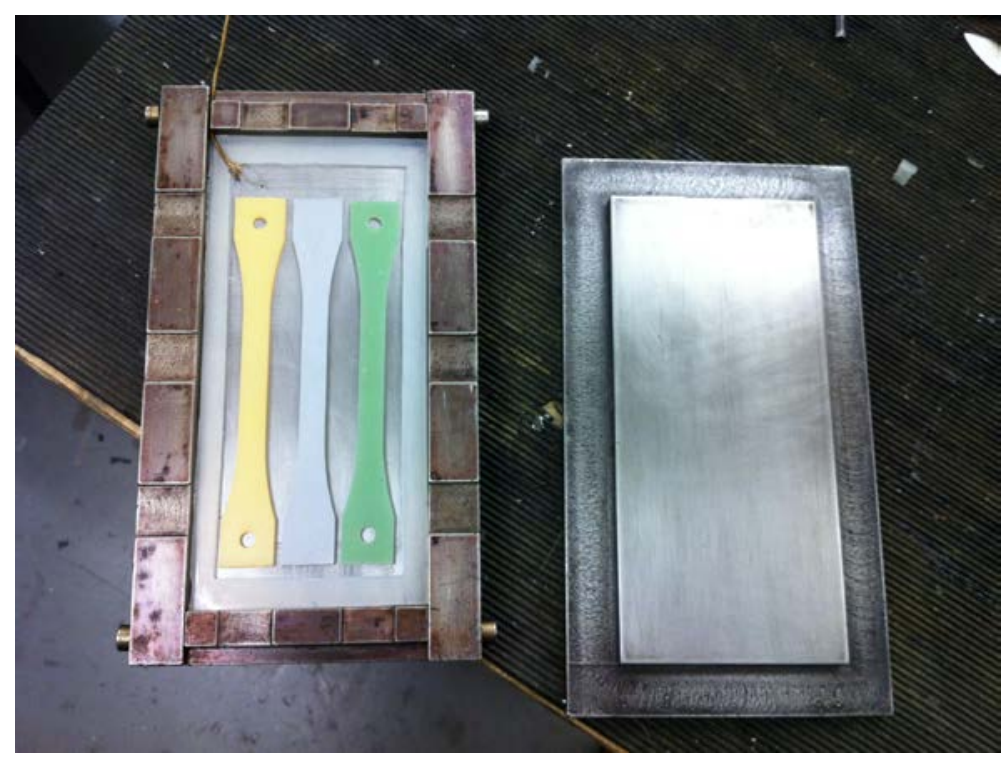

Figure 1: Mould with embedded thermocouple and sample specimens

Bulk tensile testing was performed in an INSTRON ${ }^{\circledR}$ (Norwood, Massachusetts, USA) testing machine at $1 \mathrm{~mm} / \mathrm{min}$ speed. Figure 2 presents representative stress versus strain curves for each of the curing conditions and Figure 3 shows the ultimate tensile strength of each curing condition. 


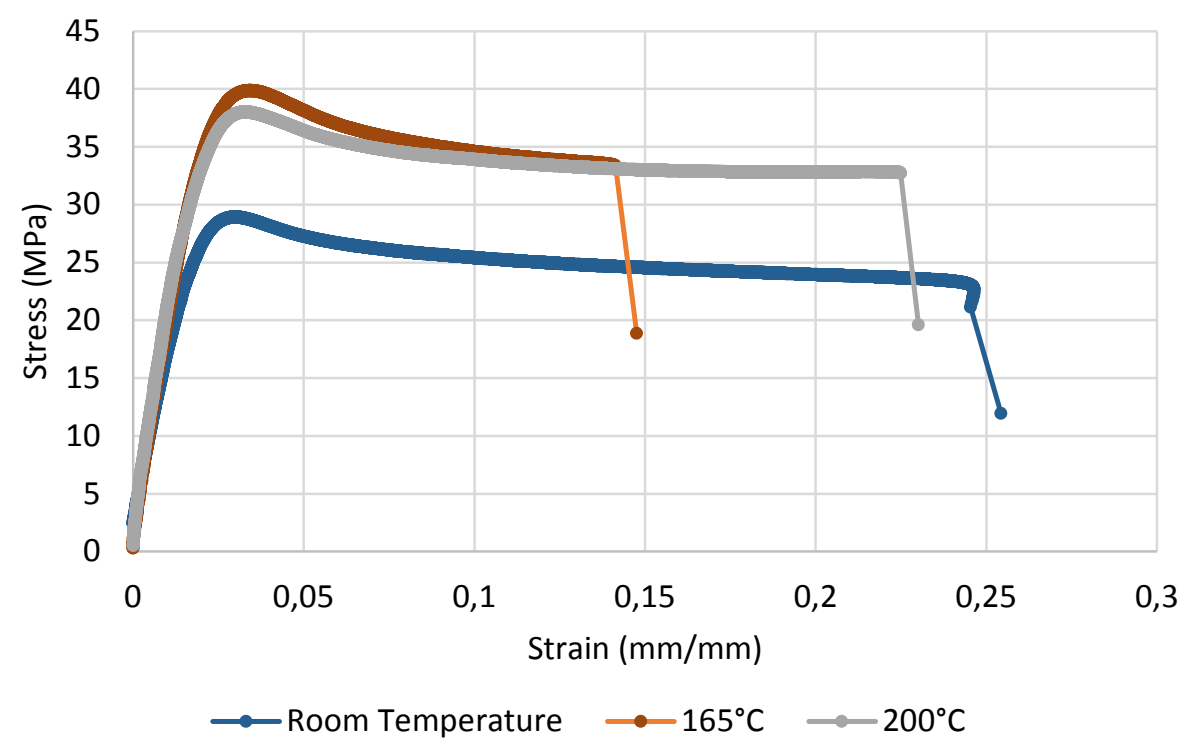

Figure 2: Stress vs. Strain curves for bulk tensile tests depending on cure condition

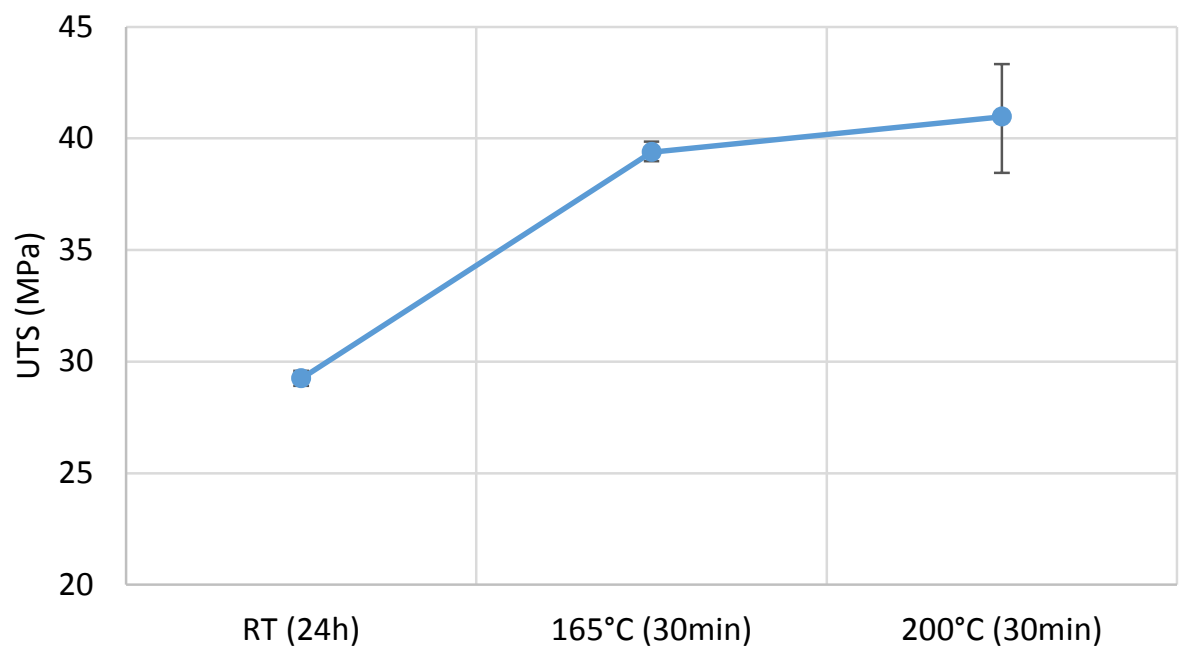

Figure 3: Ultimate tensile strength (UTS) with cure condition showing increase with cure temperature

Ultimate tensile strength increased with curing temperature although the largest increase was from room temperature to $165^{\circ} \mathrm{C}$. Stiffness measured in tensile tests was $1.85 \mathrm{GPa}$.

To assess fracture toughness, DCB specimens and ENF specimens were tested, for mode I and mode II respectively. In both DCB and ENF, steel adherents with $320 \mathrm{~mm}$ length, $25 \mathrm{~mm}$ width and $12.7 \mathrm{~mm}$ thickness were used, as shown in Figure 4. Only the room temperature cure was used for fracture tests as although in bulk tensile testing a higher temperature cure showed strength improvements the application case may not always allow these types of cures.

Data was treated using the compliance based beam method (CBBM) in mode I and II. 


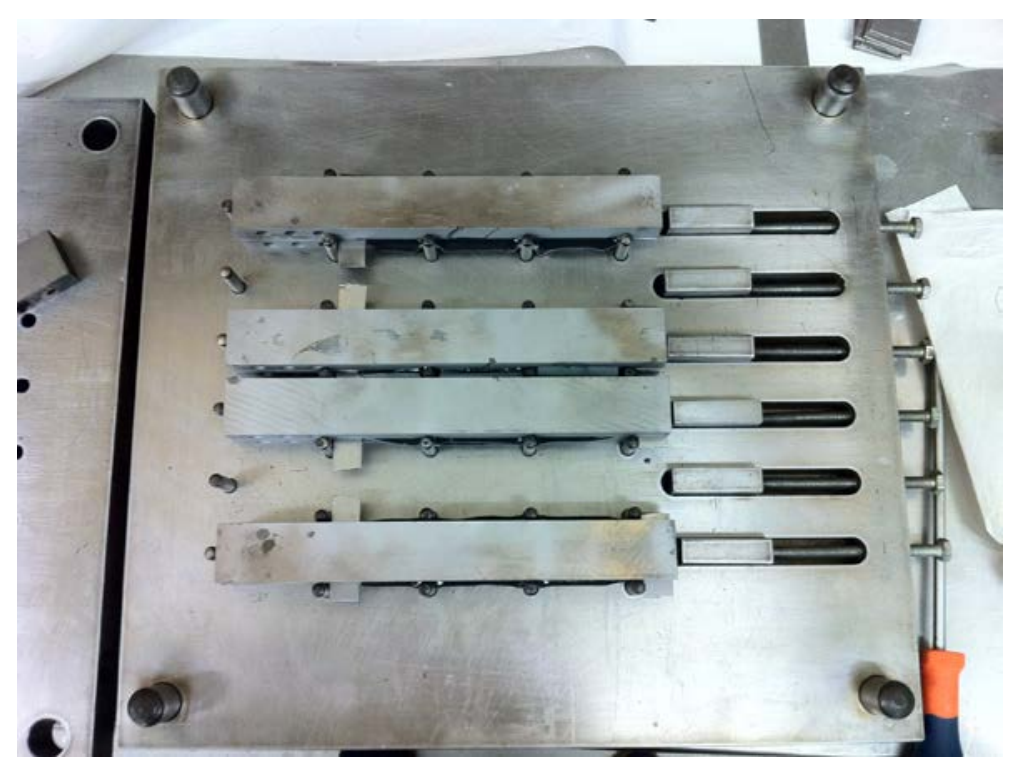

Figure 4: Fracture toughness specimens in mould

DCB specimens were tested at $1 \mathrm{~mm} / \mathrm{min}$ speed in a MTS $^{\circledR}$ (Prairie, MN USA) servo-hydraulic testing machine. Figure 5 shows a representative R-curve obtained after CBBM analysis of a DCB test.

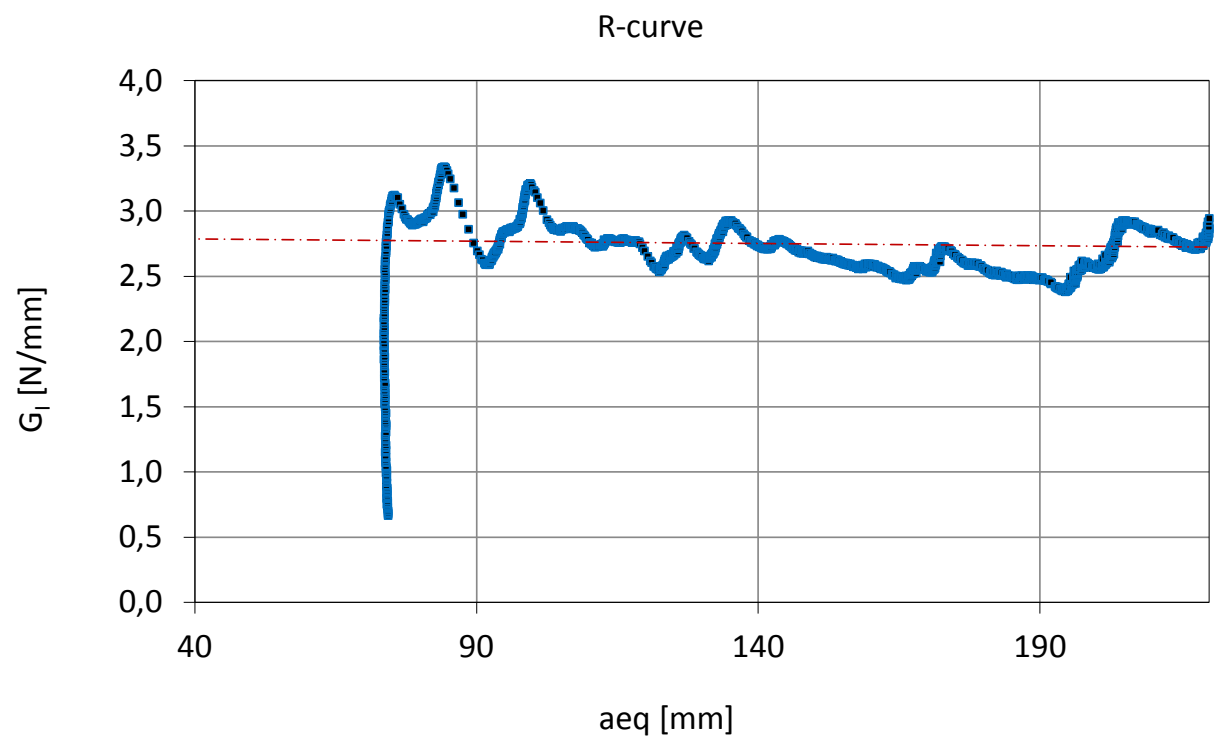

Figure 5: Representative R-curve obtained from DCB testing using CBBM

The critical fracture toughness in mode I $\left(G_{1 C}\right)$ measured measured and given by the plateau in the R-curve as the one shown in Figure 5 , was $3 \mathrm{~N} / \mathrm{mm} \pm 0.37 \mathrm{~N} / \mathrm{mm}$.

ENF testing was performed at $0.25 \mathrm{~mm} / \mathrm{min}$ speed in a $\mathrm{MTS}^{\circledR}$ (Prairie, MN USA) servo-hydraulic testing machine. A representative R-curve obtained for mode II with ENF testing is shown in Figure 6. 


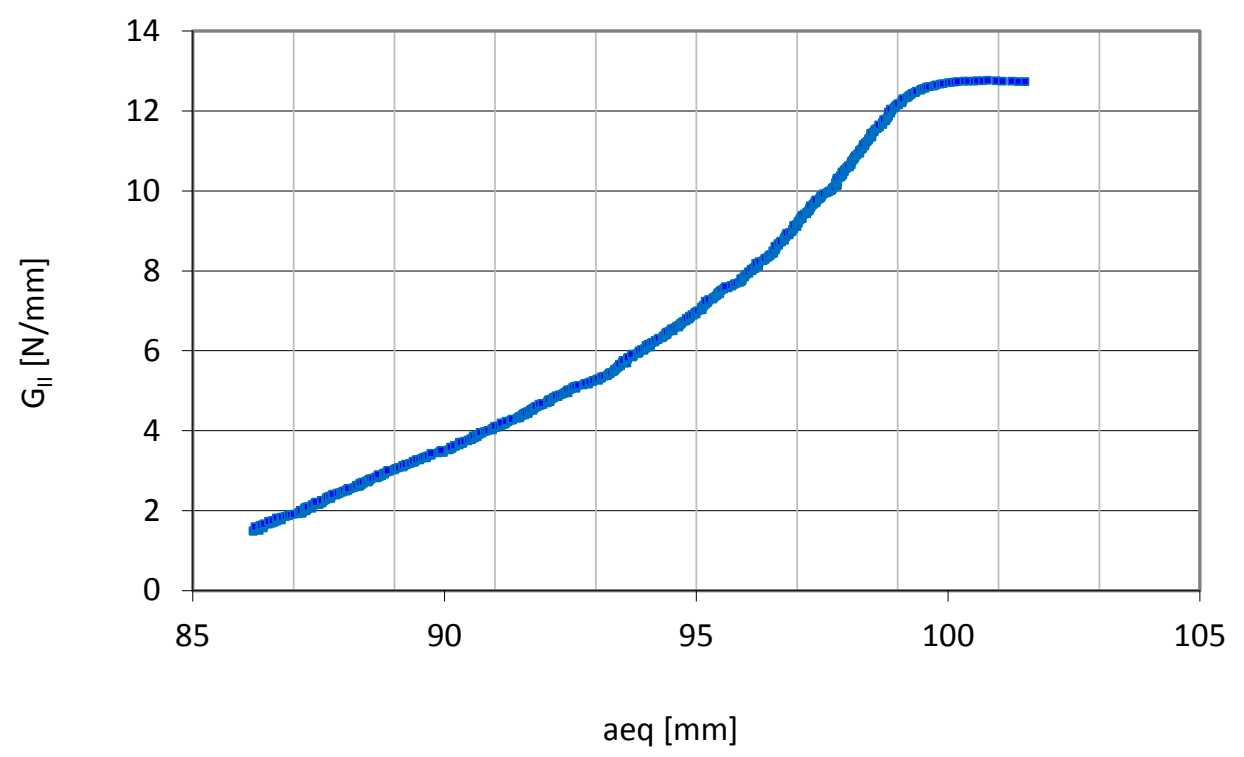

Figure 6: Representative R-curve obtained from ENF testing using CBBM

The critical fracture toughness in mode II $\left(G_{\| C}\right)$ measured and given by the plateau in the Rcurve as the one shown in Figure 6, was $12.5 \mathrm{~N} / \mathrm{mm} \pm 0.3 \mathrm{~N} / \mathrm{mm}$.

\begin{tabular}{ccccc}
\hline $\begin{array}{c}\text { Young Modulus } \\
\text { (GPa) }\end{array}$ & $\begin{array}{c}\text { UTS } \\
\text { (MPa) }\end{array}$ & $\begin{array}{c}\text { USS } \\
(\mathrm{MPa})\end{array}$ & $\begin{array}{c}\text { GIC } \\
(\mathbf{N} / \mathbf{m m})\end{array}$ & $\begin{array}{c}\text { GIIC } \\
(\mathbf{N} / \mathbf{m m})\end{array}$ \\
\hline 1.85 & 30 & 35 & 3 & 12.5 \\
\hline
\end{tabular}

Table 1 summarizes the mechanical properties of Araldite 420 epoxy adhesive when cured at room temperature for 24 hours. Ultimate shear strength (USS) was obtained from (De Moura, Daniaud, and Magalhães 2006).

\begin{tabular}{ccccc}
\hline $\begin{array}{c}\text { Young Modulus } \\
\text { (GPa) }\end{array}$ & $\begin{array}{c}\text { UTS } \\
(\mathrm{MPa})\end{array}$ & $\begin{array}{c}\text { USS } \\
(\mathrm{MPa})\end{array}$ & $\begin{array}{c}\mathrm{G}_{\mathrm{IC}} \\
(\mathbf{N} / \mathbf{m m})\end{array}$ & $\begin{array}{c}\mathrm{G}_{\text {IIC }} \\
(\mathbf{N} / \mathbf{m m})\end{array}$ \\
\hline 1.85 & 30 & 35 & 3 & 12.5 \\
\hline \multicolumn{5}{c}{}
\end{tabular}

Table 1: Summary of Araldite 420 mechanical properties

\subsection{Single lap joint testing}

Single lap joints were manufactured using $2 \mathrm{~mm}$ thick AA6082 aluminium in T6 condition. The mechanical properties of the aluminium alloy in supplied condition are listed in Table 2.

\begin{tabular}{cccc}
\hline AA6082-T6 & & \\
\hline Young's modulus & Yield strength & UTS & Elongation \\
[GPa] & {$[\mathrm{MPa}]$} & [MPa] & at failure [\%] \\
70 & $>260$ & $>310$ & 7 \\
\hline
\end{tabular}

Table 2: Mechanical properties of AA6082-T6

Two surface treatments were used, sand blasting (reference $A B-S B$ ) and phosphoric acid anodization (PAA) (reference AB-Anod) according to ASTM D3933 standard. The geometry of the single lap joints manufactured is based on ASTM D1002-01 standard and is shown in Figure 7. 

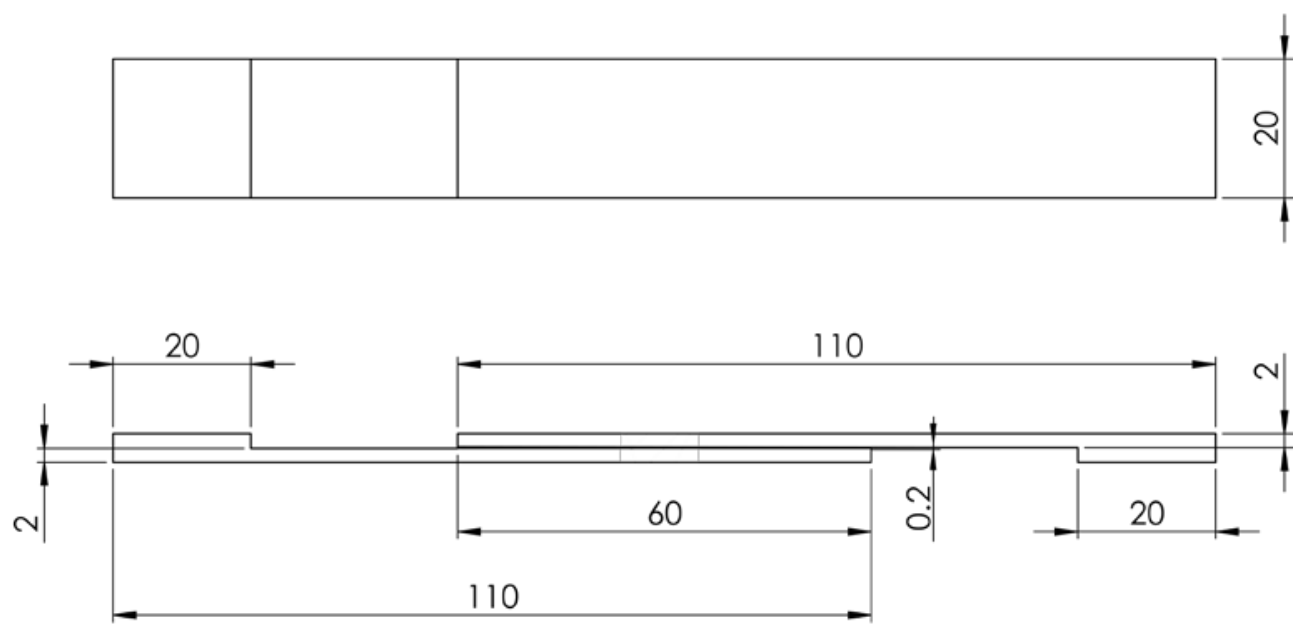

Figure 7: Single lap joint specimen geometry

The specimens (three of each) were tested in an INSTRON ${ }^{\circledR}$ (Norwood, Massachusetts, USA) testing machine at $1 \mathrm{~mm} / \mathrm{min}$ speed. Figure 8 presents a representative load versus displacement curve for each of the tested specimens.

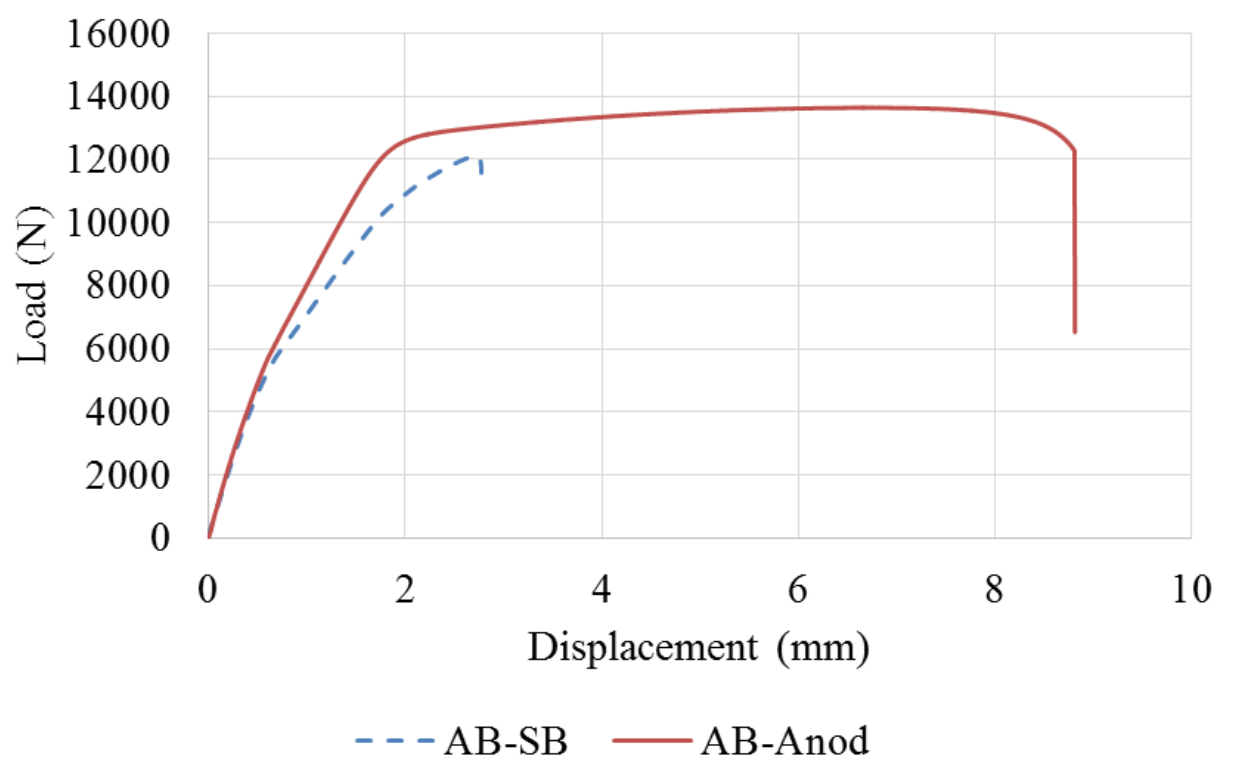

Figure 8: Load vs. displacement curves of adhesive bonded joints with sandblasted and anodized surfaces

Although a relatively small difference in ultimate load between $A B-S B\left(11.99 \mathrm{kN}_{-0.11}^{+0.13}\right)$ and $A B-$ Anod $\left(13.67 \mathrm{kN}_{-0.03}^{+0.02}\right)$, the behaviour after hitting maximum load diverges. These differences may be justified when examining the failure mechanisms, presented in Figure 9 that occurred in each specimen type. 


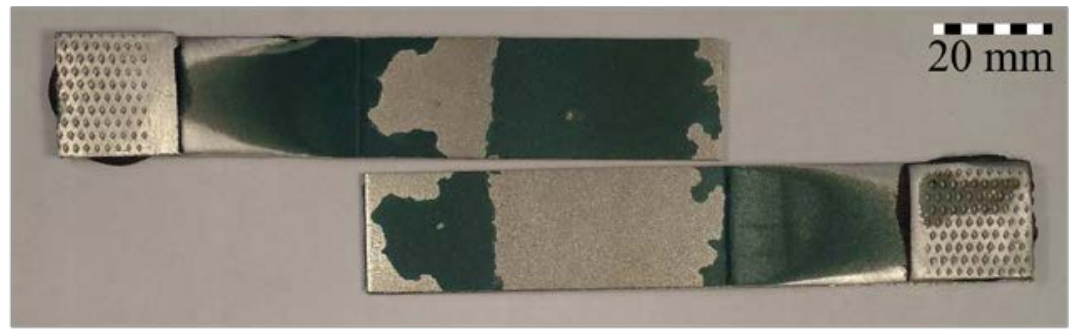

a)

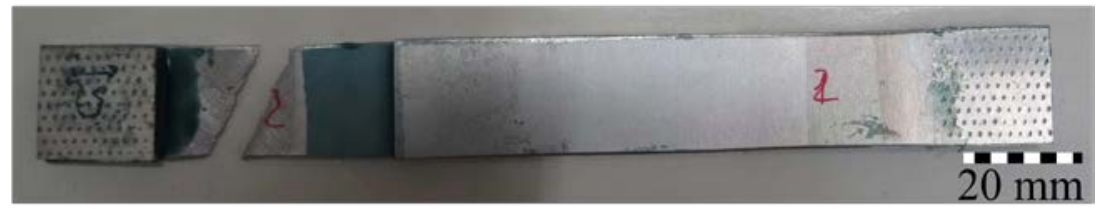

b)

Figure 9: Adhesive bonding joints specimens after testing, a) AB-SB, and b) AB-Anod

Figure 9 clearly shows adhesive failure in the sand blasted specimens while the anodized specimens did not fail in the overlap but failed in the substrate instead.

\section{Numerical Modelling}

Two numerical models were developed in Abaqus ${ }^{\mathrm{TM}}$ (Dassault Systèmes, Velizy Villacoublay, France), using a combination of 2-D plain stress elements and 2-D cohesive zone elements. The first model the DCB test mentioned previously was recreated to verify the definition of the cohesive element material properties. The model shown in Figure 10 is composed of 208982 elements, with 205000 being linear quadrilateral elements of type CPS4R and 3982 being linear quadrilateral elements of type $\mathrm{COH} 2 \mathrm{D} 4$. The average element size used was 0.5 $\mathrm{mm}$. The steel substrates are set as elastic only with a Young Modulus of $210 \mathrm{GPa}$ and Poisson ratio of 0.3 . The adhesive layer is modelled using a cohesive zone element along the thickness. Plane stress was assumed.

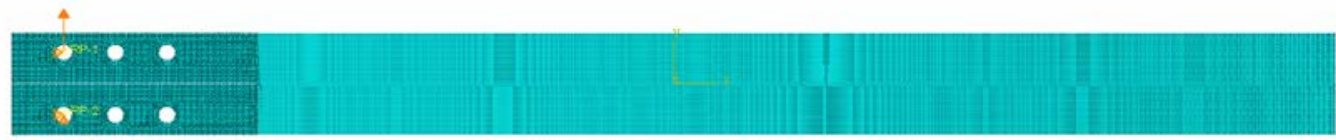

Figure 10: DCB model with mesh and loads

Good agreement between experimental results and finite element model (FEM) was found, as may be observed in Figure 11. FEM presents a slightly higher stiffness which may be justified by the way the displacement is measured in the experimental DCBs. During testing displacement is taken directly from the loading machine cylinder and as such slackness present in the whole system is included in the measurement. 


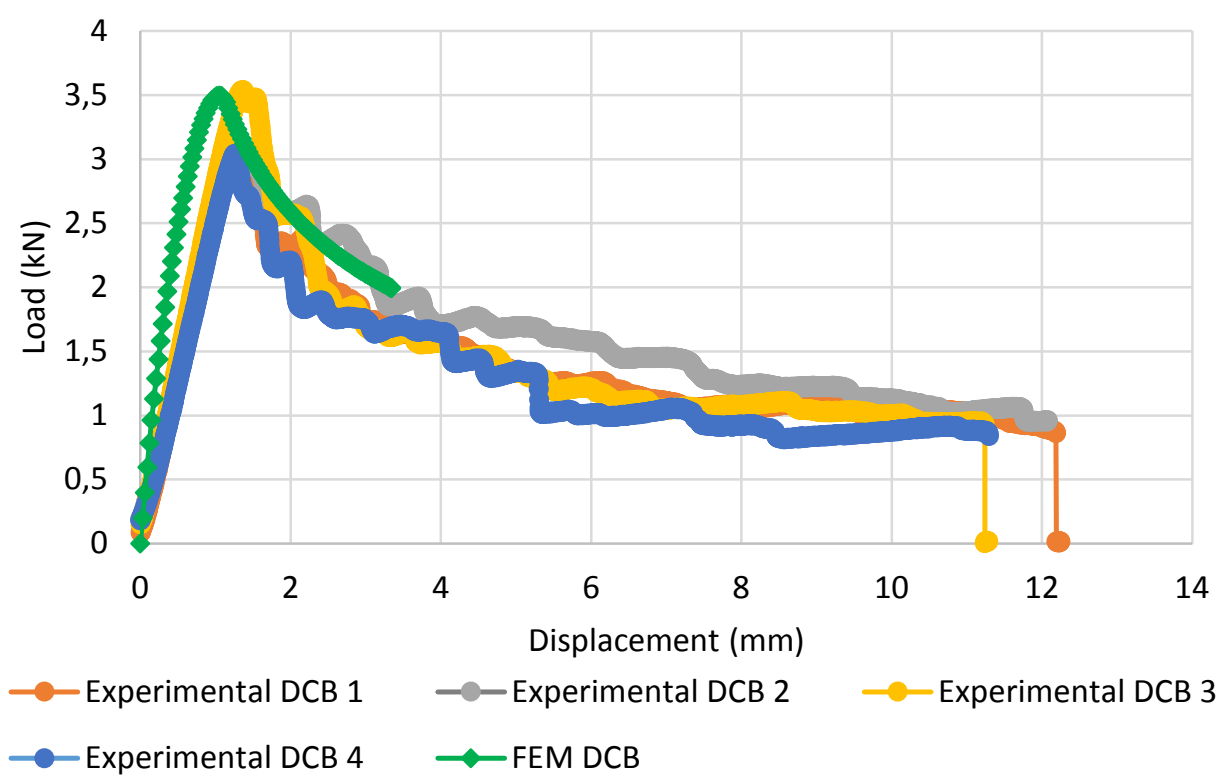

Figure 11: Load vs. displacement of experimental DCB testing and FEM model

The FEM model recreates well the maximum load achieved (difference inferior to 10\%) and the reduction in load carrying capacity from the propagation of the crack, but after a certain point it fails to converge further. Lack of convergence is an inherent problem when using cohesive zone modelling, but since the most critical phenomenon was described with success (failure initiation and propagation) it was not considered relevant to continue improving the model in order to obtain complete failure of the adhesive.

Having validated the adhesive material properties a model of the single lap joint was created using $0.1 \mathrm{~mm}$ quadratic linear elements with reduced integration (CPS4R) in the substrates region and a row of $0.1 \mathrm{~mm}$ quadratic cohesive elements (COH2D4). The AA6082-T6 material was set as linear-elastic only limiting failure to the adhesive (cohesive elements). Figure 12 shows the load versus displacement curves for FEM and experimental results, where it is possible to see the good agreement in terms of stiffness and ultimate load, although behaviour after hitting maximum load is not well discretized.
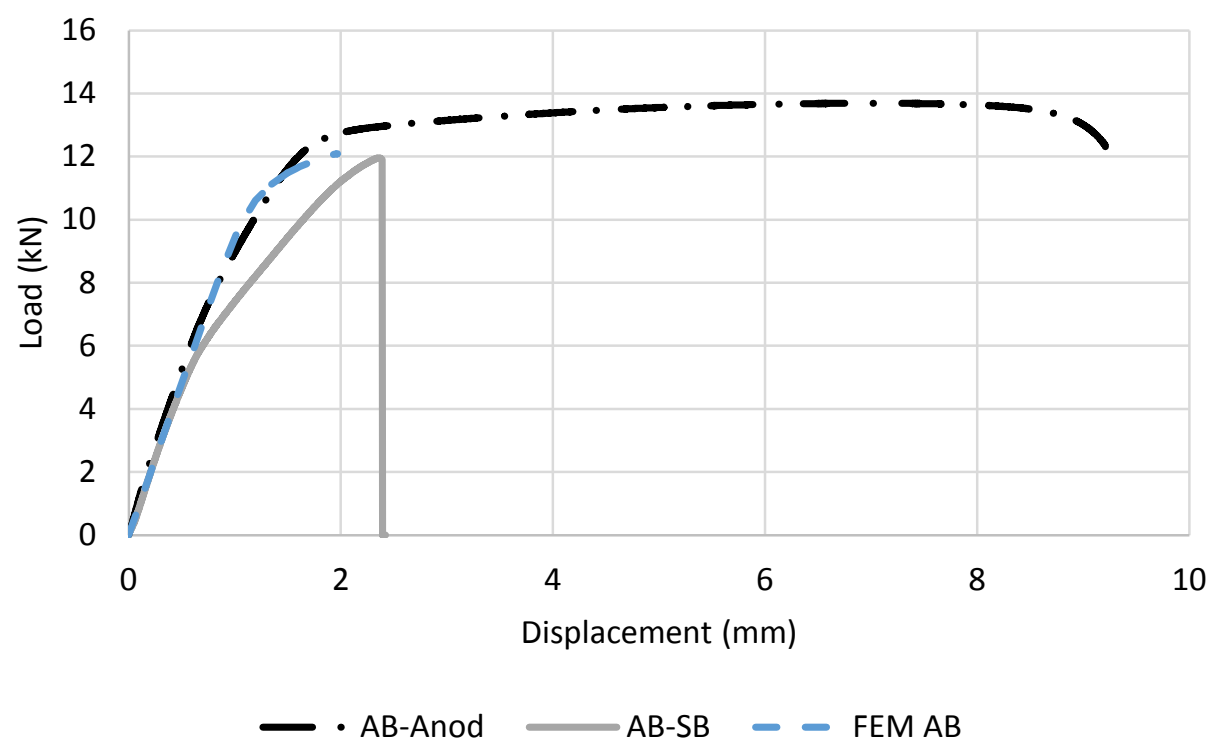

Figure 12: Representative load vs. displacement curves for numerical and experimental SLJ 
The observed differences may be due to the failure mechanisms observed in the experimental tests, as reported in Figure 9. The anodized surface plasticized and failed in the adherent, which the numerical modelling being only linear elastic cannot properly discretize. When sandblasted only, the bonding strength was not sufficient and the failure was adhesive and as such there is a loss of stiffness during test which is not observed in the numerical model.

To maximize strength of the adhesive joint and minimize plasticization of the adherent, in the future anodized surfaces and a smaller overlap should be used. Smaller overlaps also have the beneficial effect of reducing overall weight in structures where they are employed.

Although cohesive zone modelling showed capable of discretizing the cohesive failure in adhesive joints, for high toughness adhesives and large overlaps the plastic behaviour of materials should be considered as well as metallic failure using for example a Gurson Tvergaard Needleman model (Bonora et al. 2005) to recreate the failure in the adherent.

\section{Conclusions}

A successful set of experiments to characterize the adhesive Araldite 420 was undertaken in order to feed the numerical models. Single lap joints with two types of surface treatment were successfully manufactured and tested. Numerical models were built for the DCB and SL tests. Ultimate tensile strength of Araldite 420 in bulk form was shown to increase with curing temperature.

Sand blasting was shown to be an insufficient surface treatment and in order to have a strong enough bond between the aluminium and the adhesive a PAA treatment is required. However when the bond strength between aluminium and adhesive is strong enough a smaller overlap should be used if the goal is maximizing joint strength and minimizing plasticization of the substrates.

Cohesive zone modelling demonstrated the capacity to model failure in adhesive joints, but when using high strength, high fracture toughness adhesives and relatively high overlap lengths, care should be taken to the modelling of the substrates as they may become the week point in these type of joints.

\section{References}

Andersson, T., and U. Stigh. 2004. "The stress-elongation relation for an adhesive layer loaded in peel using equilibrium of energetic forces." International Journal of Solids and Structures no. 41 (2):413-434. Accessed May 11, 2016. DOI: 10.1016/j.ijsolstr.2003.09.039.

Banea, Mariana D., Lucas F. M. da Silva, Raul D. S. G. Campilho, and Chiaki Sato. 2014. "Smart adhesive joints: An overview of recent developments." The Journal of Adhesion no. 90 (1):16-40. Accessed May 11, 2016. DOI: 10.1080/00218464.2013.785916.

Bonora, Nicola, Domenico Gentile, A. Pirondi, and Golam Newaz. 2005. "Ductile damage evolution under triaxial state of stress: theory and experiments." International Journal of Plasticity no. 21 (5):981-1007. Accessed May 11, 2016. DOI: 10.1016/j.ijplas.2004.06.003.

Campilho, Raul D. S. G., Mariana D. Banea, and Lucas F. M. da Silva. 2013. "Tensile behaviour of a structural adhesive at high temperatures by the extended finite element method." The Journal of Adhesion no. 89 (7):529-547. Accessed May 11, 2016. DOI: 10.1080/00218464.2013.768106.

Campilho, Raul D.S.G., Marcelo F.S.F. de Moura, Dimitra A. Ramantani, and João P.M. Gonçalves. 2008. "Obtaining the cohesive laws of a trapezoidal mixed-mode damage model using an inverse method." Ciência \& Tecnologia dos Materiais no. 20:81-86. Accessed May 
11, 2016. http://www.scielo.mec.pt/scielo.php?script=sci_arttext\&pid=S0870$83122008000100012 \& n r m=i s o$.

Chaves, Filipe J. P., Marcelo F. S. F. de Moura, Lucas. F. M. da Silva, and D. A. Dillard. 2014. "Fracture characterization of bonded joints using the dual actuator load apparatus." Journal of Adhesion Science and Technology no. 28 (5):512-524. Accessed May 11, 2016. DOI: 10.1080/01694243.2013.845357.

de Moura, Marcelo F. S. F. 2006. "Numerical simulation of the ENF test for the mode-II fracture characterization of bonded joints." Journal of Adhesion Science and Technology no. 20 (1):37-52. Accessed May 11, 2016. DOI: 10.1163/156856106775212422.

de Moura, M. F. S. F., R. Daniaud, and A. G. Magalhães. 2006. "Simulation of mechanical behaviour of composite bonded joints containing strip defects." International Journal of Adhesion and Adhesives no. 26 (6):464-473. Accessed May 11, 2016. DOI: 10.1016/j.ijadhadh.2005.06.010.

Gonçalves, Daniel J. S., Raul D. S. G. Campilho, Lucas F. M. Da Silva, and J. L. M. Fernandes. 2014. "The use of the boundary element method in the analysis of single lap joints." The Journal of Adhesion no. 90 (1):50-64. Accessed May 11, 2016. DOI: 10.1080/00218464.2013.763725.

Gu, Yuanqing, and Nicole S. Zacharia. 2015. "Self-healing actuating adhesive based on polyelectrolyte multilayers." Advanced Functional Materials no. 25 (24):3785-3792. Accessed May 11, 2016. DOI: 10.1002/adfm.201501055.

Kadioglu, Ferhat, and Robert D. Adams. 2015. "Flexible adhesives for automotive application under impact loading." International Journal of Adhesion and Adhesives no. 56:73-78. Accessed May 11, 2016. DOI: 10.1016/j.ijadhadh.2014.08.001.

Marques, E. A. S., L. F. M. da Silva, M. D. Banea, and R. J. C. Carbas. 2015. "Adhesive joints for low-and high-temperature use: An overview." The Journal of Adhesion no. 91 (7):556-585. Accessed May 11, 2016. DOI: 10.1080/00218464.2014.943395.

Pethrick, Richard A. 2014. "Design and ageing of adhesives for structural adhesive bonding A review." Proceedings of the Institution of Mechanical Engineers, Part L: Journal of Materials Design and Applications. Accessed May 11, 2016. DOI: $10.1177 / 1464420714522981$.

Sauer, Roger A. 2016. "A survey of computational models for adhesion." The Journal of Adhesion no. 92 (2):81-120. Accessed May 11, 2016. DOI: 10.1080/00218464.2014.1003210.

Schiel, M., S. Kreling, C. Unger, F. Fischer, and K. Dilger. 2015. "Behavior of adhesively bonded coated steel for automotive applications under impact loads." International Journal of Adhesion and Adhesives no. 56:32-40. Accessed May 11, 2016. DOI: 10.1016/j.ijadhadh.2014.07.009.

Xia, Lanjun, Lu Zuo, Shangwen Zha, Shufang Jiang, Rong Guan, and Deping Lu. 2014. "Kinetic research on low-temperature cure of epoxy adhesive." International Journal of Adhesion and Adhesives no. 50:255-264. Accessed May 11, 2016. DOI: 10.1016/j.ijadhadh.2014.02.005.

Xie, Jiang, Hong-jie Sun, Xue-zhong Zhang, Ze-min Xie, and Zhi-jie Zhang. 2015. "Carboranecontaining solvent-free liquid silicone resin: synthesis, characterization, and hightemperature adhesive properties." Phosphorus, Sulfur, and Silicon and the Related $\begin{array}{lllll}\text { Elements no. } 190 & \text { (3):277-291. Accessed May 11, 2016. DOI: }\end{array}$ 10.1080/10426507.2014.938992. 